\title{
Some Comparative Performance and Emission Studies on DI Diesel Engine Fumigated with Methanol and Methyl Ethyl Ketone Using Microprocessor Controlled Fumigator
}

\author{
C. Sundar Raj ${ }^{*}, 1$, S. Arul $^{2}$ and S. Senthilvelan ${ }^{3}$ \\ ${ }^{I}$ Dr. MGR Educational and research institute, Dr. MGR University, Chennai Professor, Department of Mechanical \\ Engineering, Bharathiyar College of Engineering and Technology, Karaikal, Pondicherry 609 609, India \\ ${ }^{2}$ Department of Mechanical Engineering, ${ }^{3}$ Dr. MGR Educational and research institute, Dr. MGR University, Chennai, \\ India
}

\begin{abstract}
The main objective of this study is to improve the performance and cleaning up of diesel engine's exhaust by fumigating known quantity of methanol and methyl ethyl ketone individually using a custom made Electronic fuel injector controlled by a microprocessor. To control the emission from diesel engine and to improve performance, alternate fuel and in-cylinder control techniques are used. The experimental study has been carried out in a single cylinder diesel engine. The experimental set-up is such that known quantity of methyl ethyl ketone is fumigated in the intake manifold using a microprocessor controlled electronic fuel injector. Results of the experimental study of a DI Diesel engine are presented, which show the influence of partial premixing fumigation of the intake air with methanol and methyl ethyl ketone fuel on the exhaust emissions and the engine performance parameters The result shows an appreciable reduction of emissions, such as, oxides of nitrogen, smoke density and marginal increase in the performance in fumigation mode for both the fuels and are compared with those of normal diesel engine.
\end{abstract}

\section{INTRODUCTION}

Reducing the emissions and fuel consumption are no longer future goals; instead they are the demands of the day. Alcohols are examples of the most attractive alternative nonpetroleum fuels used in internal-combustion engines. Although there are a lot of studies on the use of alcohols in spark ignition engines, in the past, little attention has been given to the utilization of alcohols in diesel engines. This is due to the difficulties encountered while attempting to use alcohols in diesel engines, especially at high alcohol ratios, which are summarized as follows [1-5]:

1. Alcohols have very poor lubricating characteristics.

2. The heating value of alcohol is less than that of diesel fuel; therefore, more alcohol than diesel fuel is required by mass and volume.

Although replacing diesel fuel entirely by alcohols is very difficult, an increased interest has emerged for the use of alcohols, and particularly the lower alcohols such as methanol and ethanol, with different amounts and different techniques in diesel engines as a dual fuel operation during recent years [4]. These techniques can be generally classified into three categories:

1. Alcohol-diesel fuel blend: mixing fuels in the fuel tank, displacing up to $25 \%$ of diesel fuel demand.

2. Dual injection: separate injection system for each fuel, displacing up to $90 \%$ of diesel fuel demand.

*Address correspondence to this author at the Department of Mechanical Engineering, Bharathiyar College of Engineering and Technology, Karaikal 609609 UT of Puducherry, India; E-mail: csundarraj@yahoo.com
3. Alcohol fumigation: the addition of alcohols to the intake air charge, displacing up to $50 \%$ of diesel fuel demand.

The most attractive and the simplest one of these techniques we are concerned with in this study is alcohol fumigation for diesel engines. Fumigation is a technique by which alcohol is introduced in the intake air flow by a simple carburetor and vaporizing it or injecting alcohol in the intake air stream. This requires the addition of a carburetor, a vaporizer or an injector, along with a separate fuel tank, lines and control [4]. However, using a simple carburetor requires a simple modification on the engine intake system, and thus, this method is fairly cheap. Thus, it is considered that instantaneous burning of air and LF mixture could form swirl motions and additional gas motions in the cylinder and this could mix rather well diesel fuel, air and LF mixture. As a result, engine performance could improve and nitrogen oxides could decrease because of faster and efficient burning of the fuel [6]. Most of these studies are focused on to calculate the dimensions of carburetor for fumigation as there is no specific device in any model to find the volume of LF inducted. In this work the performance and emissions are studied by adapting a microprocessor controlled electronic pump with injector to control the LF flow rate. Experiments were conducted for various fumigation rates of two different LF (methanol and methyl ethyl ketone) and the results were compared.

\section{ELECTRONIC FUEL INJECTOR}

An electronic fuel injection kit as shown in Fig. (1) is used for fumigation. The fumigating fuel is pumped in to the injector by an electronic pump and the number of pulses of the injector is controlled by an AT-89C52 microprocessor. 


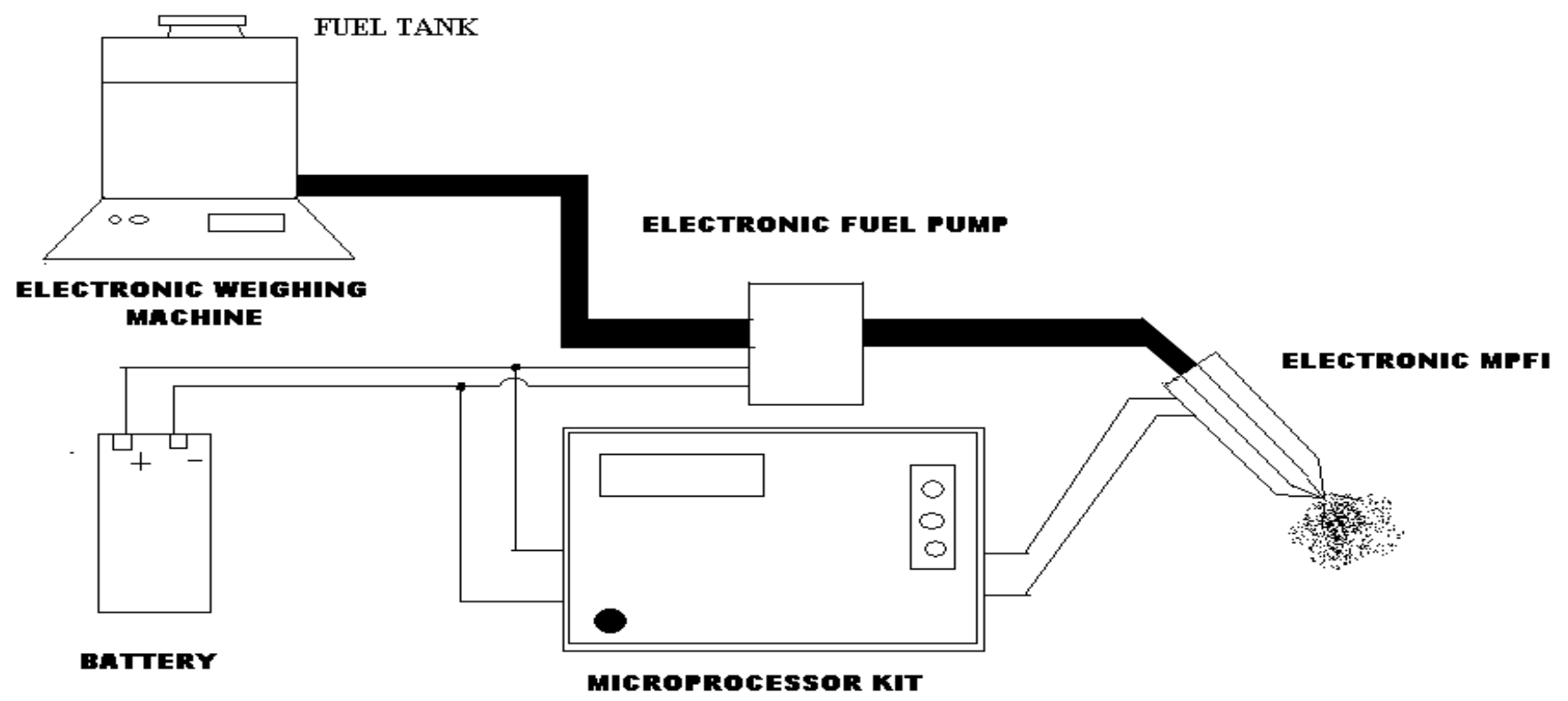

Fig. (1). Layout of Electronic Fuel Injection Kit.

The quantity of fuel injected per pulse can be calibrated by adjusting the number of pulses per minute and hence a constant volume of LF can be fumigated at any working condition

\section{Table 1. Specification for Kirloskar Diesel Engine}

\begin{tabular}{|c|c|}
\hline Type of engine & Single cylinder DI Diesel engine \\
Type of cooling & Air \\
Engine power & $5 \mathrm{hp}$ \\
Bore and stroke & $87.5 \times 110 \mathrm{~mm}$ \\
Compression ratio & $17.5: 1$ \\
Speed & $1500 \mathrm{rpm}$ \\
\hline
\end{tabular}

Table 2. Properties of Methanol and Methyl Ethyl Ketone

\begin{tabular}{|l|c|c|}
\hline \multicolumn{3}{|c|}{ Properties } \\
\hline \hline Molecular Formula & $\mathrm{C}_{4} \mathrm{H}_{8} \mathrm{OCH}_{3} \mathrm{COC}_{2} \mathrm{H}_{5}$ & $\mathrm{CH}_{3} \mathrm{OH}$ \\
\hline Molar mass & $72.11 \mathrm{~g} / \mathrm{mol}$ & $32.04 \mathrm{~g} / \mathrm{mol}$ \\
\hline Appearance & Colourless liquid & Colourless liquid \\
\hline Density & $952 \mathrm{~kg} / \mathrm{m} 3$ & $791.8 \mathrm{Kg} / \mathrm{m}^{3}$ \\
\hline Melting point & $-86{ }^{\circ} \mathrm{C}$ & $-97^{\circ} \mathrm{C}$ \\
\hline Boiling point & $80{ }^{\circ} \mathrm{C}$ & $64.7^{\circ} \mathrm{C}$ \\
\hline Solubility in water & $29 \mathrm{~g} / 100 \mathrm{ml}\left(20^{\circ} \mathrm{C}\right)$ & Fully miscible \\
\hline Calorific Value & $13228 \mathrm{~kJ} / \mathrm{kg}$ & $11778 \mathrm{KJ} / \mathrm{Kg}$ \\
\hline
\end{tabular}

\section{EXPERIMENTAL SETUP}

The experimental set up is shown in Fig. (2). The experimental system includes the engine, air flow and emission measurement system. The engine is connected to an eddy current dynamometer. Airflow rate was measured by means of anemometer. An exhaust gas analyzer (AVL Five gas analyzer) was used for measuring the exhaust emissions like oxides of nitrogen, hydrocarbons, carbon monoxide and carbon dioxide $\left(\mathrm{NOx}, \mathrm{HC}, \mathrm{CO}, \mathrm{CO}_{2}\right)$ Exhaust gas temperature was measured by means of a $\mathrm{K}$ - type thermocouple. The LF is injected in to the inlet manifold through microprocessor injection kit. Experiments were conducted with neat diesel and fumigating with Methanol and Methyl ethyl ketone individually at a rate of $0.2,0.4$, $0.6,0.8,1.0 \mathrm{gm} / \mathrm{min}$ by adjusting the pulse setter in the microcontroller and the optimum value of each LF for performance was found out at $50 \%, 75 \%$ and $100 \%$ of load. The emission at various loads for optimum flow of LF were studied and compared.

\section{RESULTS}

The variation of Brake thermal efficiency at 50\%, 75\% and $100 \%$ load for base diesel fuel and for various fumigation rates with methanol and methyl ethyl ketone is shown in Figs. (3) and (4). It can be observed that the brake thermal efficiency is maximum at $0.4 \mathrm{gm} / \mathrm{min}$ of methanol fumigation and $0.8 \mathrm{gm} / \mathrm{min}$ of methyl ethyl ketone fumigation. The increase in efficiency for methanol is high comparing with methyl ethyl ketone as the number of $\mathrm{C}$ and $\mathrm{H}$ atoms are more in methyl ethyl ketone

Fig. (5). shows the variation of brake thermal efficiency at various loading conditions for neat diesel and optimum fumigating conditions for metanol and methl ethyl ketone. The efficency is increased in fumigating mode and a maximum of $3.3 \%$ at full load is recorded for methanol fumigation.

The variation of oxides of nitrogen with load for base diesel fuel and optimum fumigating conditions for metanol and methl ethyl ketone is depicted in Fig. (6) Both the fumigators reduces $\mathrm{NOx}$ concentration almost in equal manner and the maximum reduction is $48 \%$ at full load for metanol fumigation when compared to base diesel fuel. 


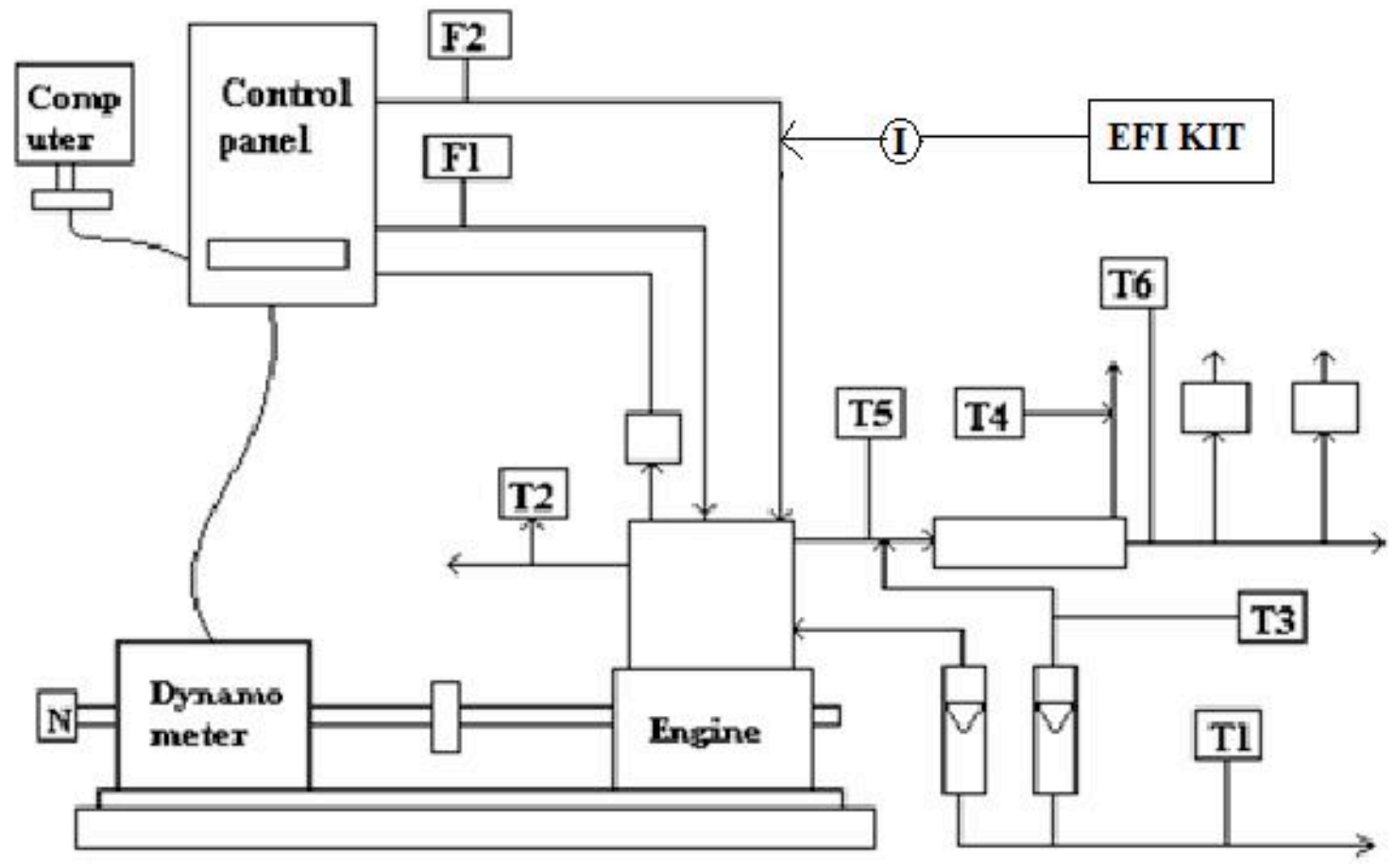

T1\&T3 - Inlet water temp in ${ }^{\circ} \mathrm{C}$

T2-Outlet engine water temp in ${ }^{\circ} \mathrm{C}$

T4-Outlet calorimeter water temp in ${ }^{\circ} \mathrm{C}$ T5-Exhaust gas temp ${ }^{\circ} \mathrm{C}$ before calorimeter

T6-Exhaust gas temp ${ }^{\circ} \mathrm{C}$ after calorimeter

$\mathrm{N}$ - RPM decoder

F1 - Fuel flow differential weight unit

F2 - Air flow differential velocity unit

I - Electronic Injector

Fig. (2). Experimental setup.

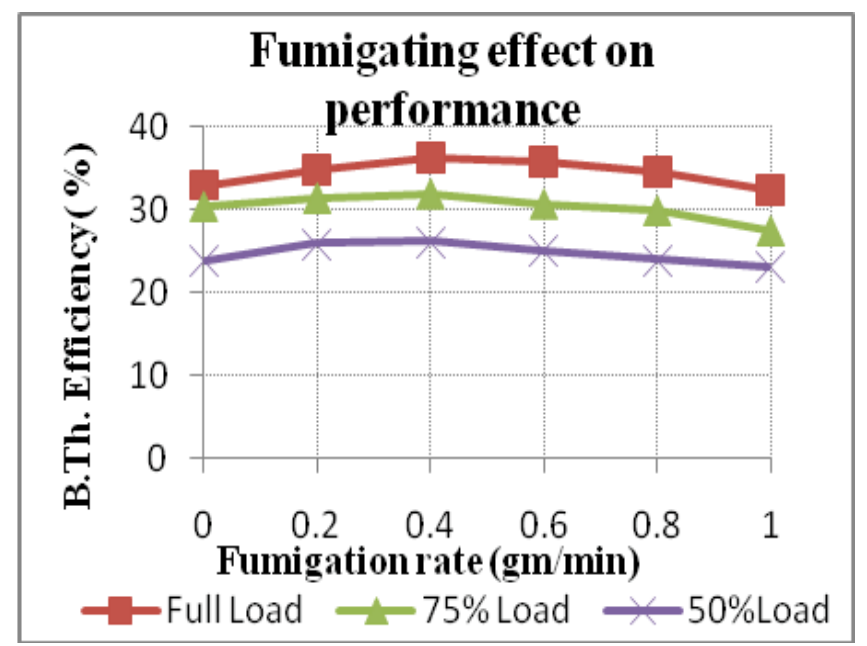

Fig. (3). variation of brake thermal efficiency for methanol fumigation.

Fig. (7) depicts the variation of smoke opacity with load for base diesel fuel and optimum fumigating condition. The smoke in the engine exhaust is gradually reduced during loading for fumigating condition compared to base diesel fuel. $34 \%$ reduction was obseved at full load for MEKfumigated and $25 \%$ for metanol fumigated fuel comparing with neat diesel.

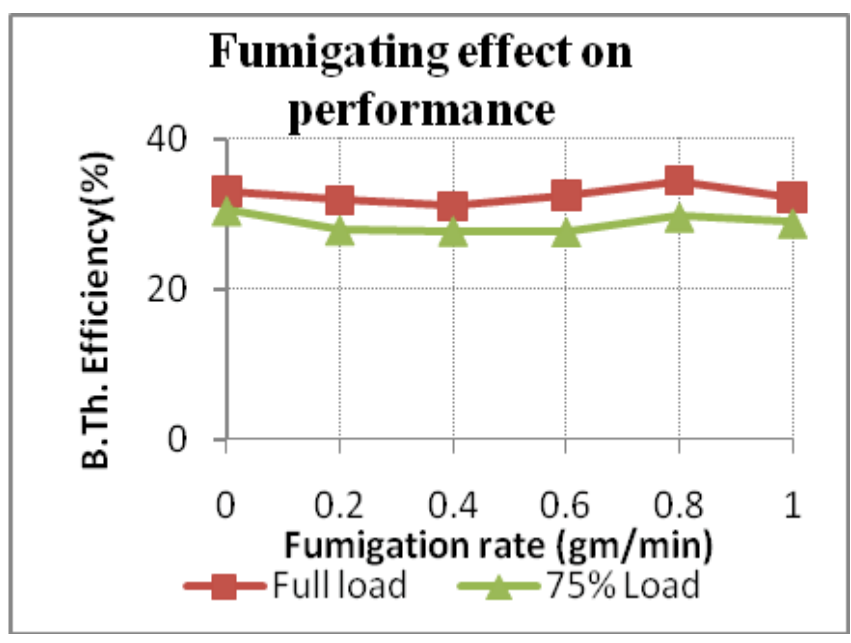

Fig. (4). variation of brake thermal efficiency for methyl ethyl ketone fumigation.

It can be observed from the Fig. (8) that $\mathrm{HC}$ emission increased by $67.5 \%$ and $48 \%$ respectively at no load for methanol and MEK fumigated fuel when compared to the base diesel fuel. The increase in $\mathrm{HC}$ may be due to the quenching layer generated on the wall surface of the combustion chamber by the LF mixture as in SI engine. However as invented by Daniel (1967) the generated quench 


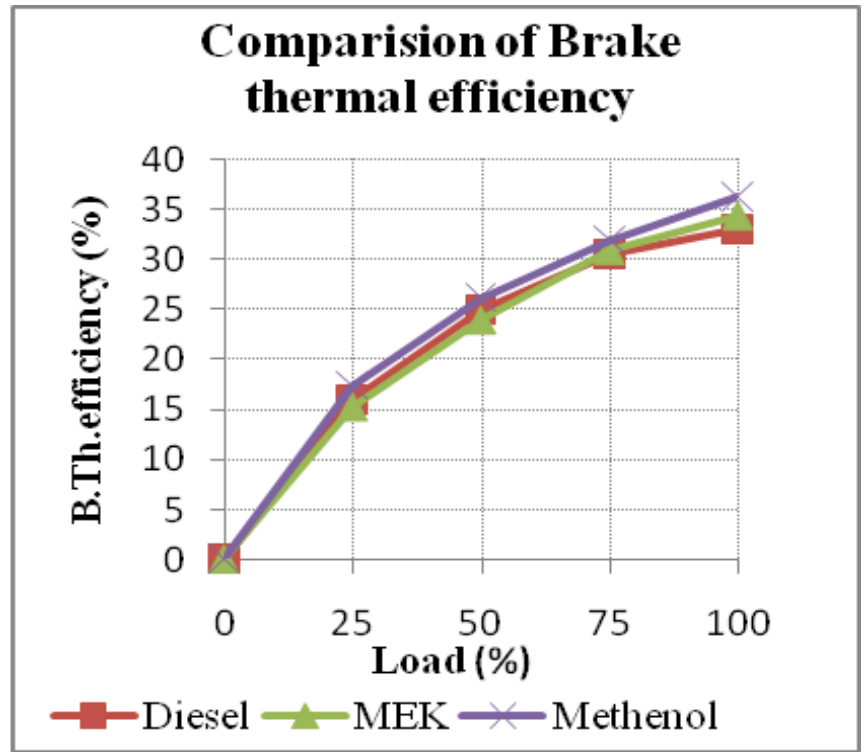

Fig. (5). Variation of brake thermal efficiency with load.

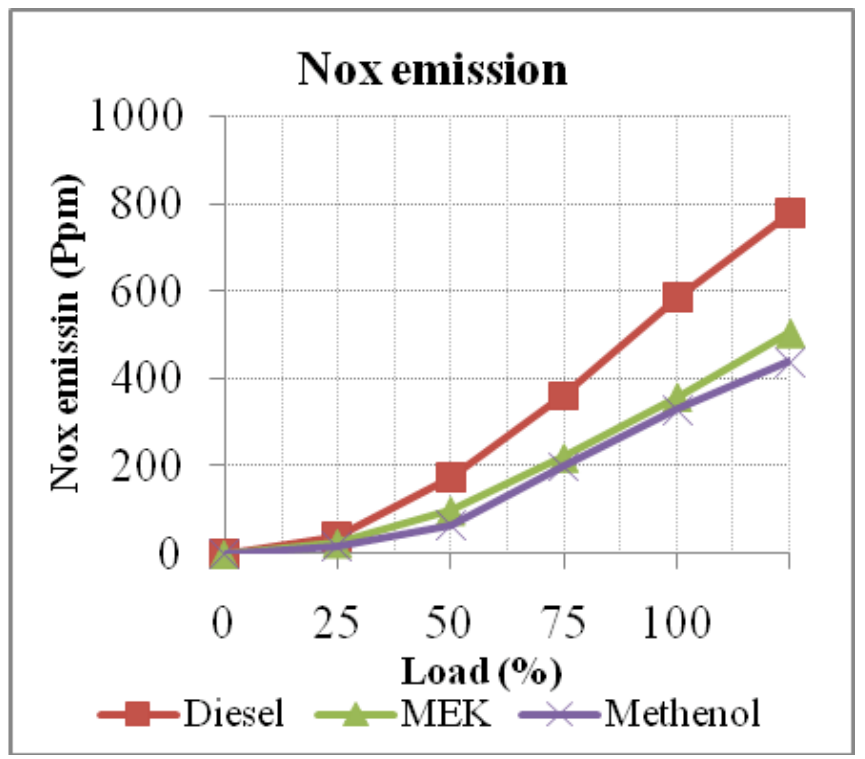

Fig. (6). Variation of NOx with load.

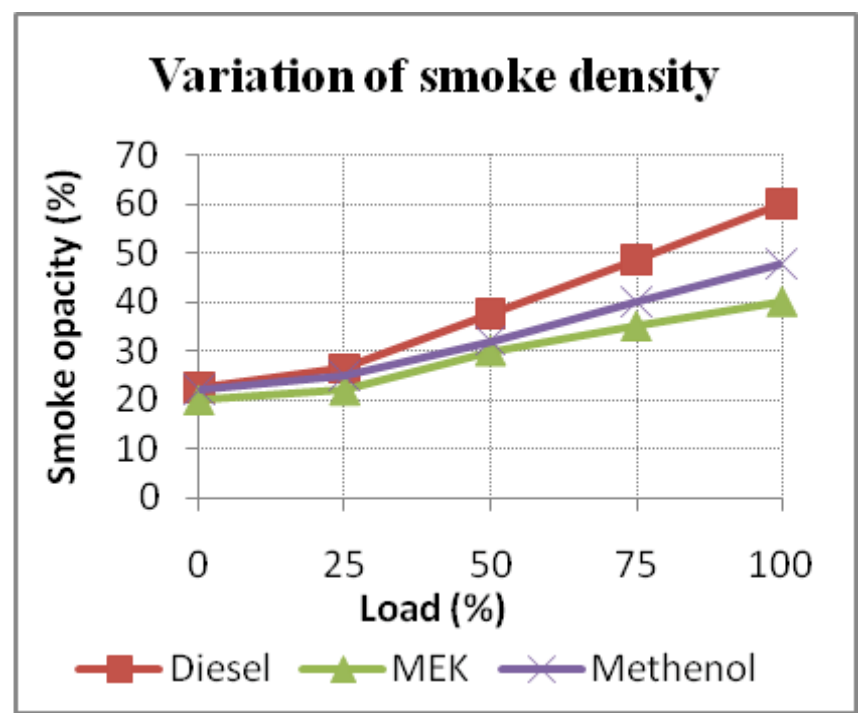

Fig. (7). Variation of smoke opacity with load.

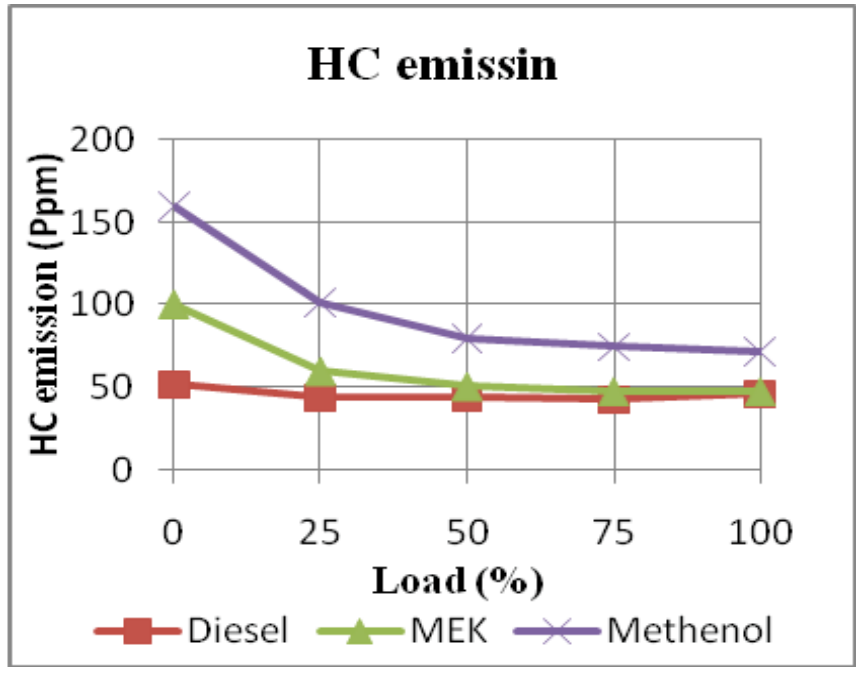

Fig. (8). Variation of $\mathrm{HC}$ with load.

layer is oxidized by diffusion after expansion, and hence the amount of $\mathrm{HC}$ reduces during loading. It can also be due to the loss of some of the fumigated charge through exhaust valve during the overlap period. The difference is reduced to $20 \%$ and $3 \%$ respectively at full load.

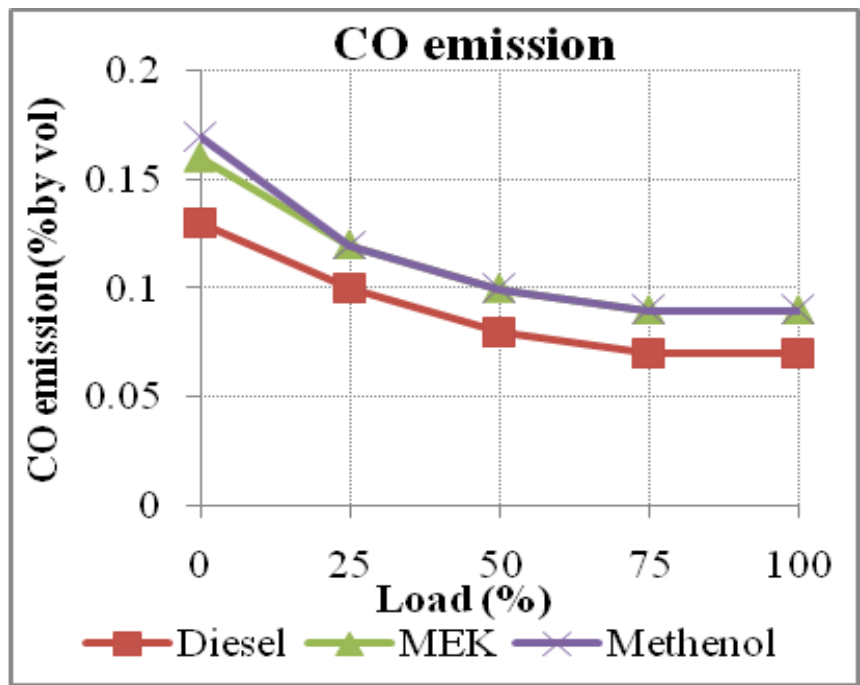

Fig. (9). Variation of $\mathrm{CO}$ with load.

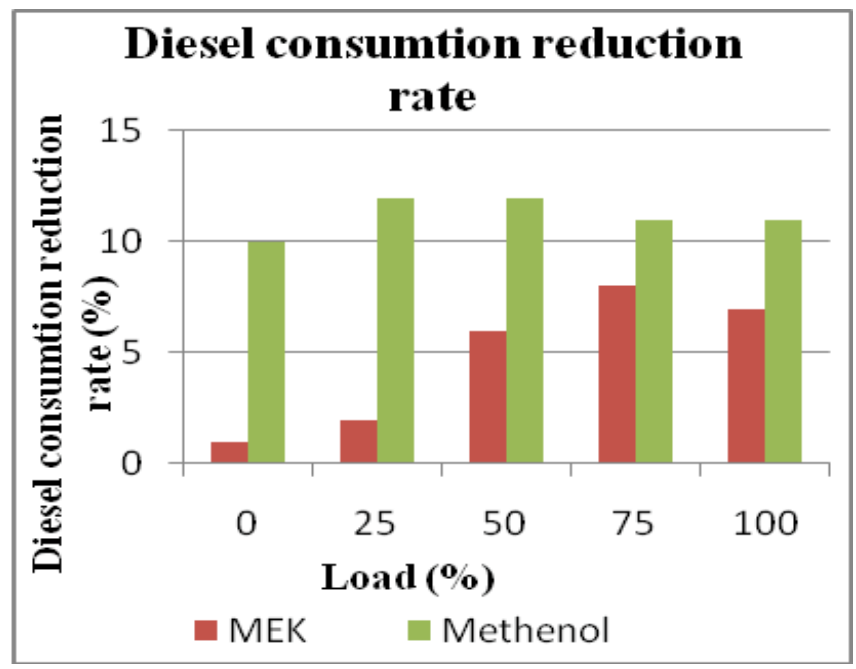

Fig. (10). Diesel consumption. 
The variation of $\mathrm{CO}$ emission with load for base diesel fuel and optimum fumigating condition with metanol and MEK is shown in Fig. (9). It can be observed that $\mathrm{CO}$ emission increased by $22 \%$ at full load in the case of fumigation for both the fuels when compared to the base diesel fuel. This may be due to the combustion of fumigated methenol is more like a homogeneous charge.

It is also observed from Fig. (9) that $11.5 \%, 7 \%$ of diesel consumption is reduced when it is fumigated with 0.4 $\mathrm{gm} / \mathrm{min}$ of methenol and $0.8 \mathrm{gm} / \mathrm{min}$ of MEK respectively.

\section{DISCUSSION AND CONCLUSIONS}

The results obtained in this investigations are as follows:

Brake thermal efficiency at $50 \%, 75 \%$, Full load is maximum at $0.4 \mathrm{gm} / \mathrm{min}$ of methanol mixture and $0.8 \mathrm{gm} / \mathrm{min}$ of MEK mixture then decreases indicated that the optimum fumigation is $0.4 \mathrm{gm} / \mathrm{min} 0.8 \mathrm{gm} / \mathrm{min}$ for metanol and MEK mixture respectively

$>$ Oxides of nitrogen emissions can be substantially reduced in fumigation with both the fuels

$>$ Carbon monoxide emission increased in fumigation mode

$>\quad$ Unburned hydrocarbons increased greately with fumigated fuel and is relatively high for methenol fumigation

$>\quad$ Smoke emission is considerably reduced at high loading conditions for fumigated fuel and the reduction is high for MEK fumigation compared with metanol
Diesel consumption rate is greately reduced in fumigated mode for metanol than the MEK
ABBREVIATIONS
${ }^{\mathrm{o}} \mathrm{C}=$ Degree centigrade
bhp $=$ Brake horse power
$\mathrm{KJ} / \mathrm{Kg}=$ Kilo joules per kilogram
Ppm $=$ Parts per million
LF $\quad=$ Light fuel
LFM = Light fuel mixture
MEK = Methyl ethyl ketone

\section{REFERENCES}

[1] Ajav, E.A.; Singh, B.; Bhattacharya, T.K. Experimental study of some performance parameters of a constant speed stationary diesel engine using ethanol-diesel blends as fuel. Biomass Bioenergy, 1999, 17, 357-365.

[2] Sahin, Z. Thesis. KTU graduate school of natural and applied sciences, Trabzon, 2002.

[3] Chen, J.; Gussert, D.; Gao, X.; Gupta C.; Foster D. Ethanol fumigation of a turbocharged diesel engine. SAE, 1981, 810680, 114.

[4] Abu-Qudais, M.; Haddad, O.; Qudaisat. M. The effect of alcohol fumigation on diesel engine performance and emissions. Energy Convers. Manag., 2000, 41, 389-399.

[5] Bilgin, A.; Durgun O.; Sahin, Z. The effect of diesel-ethanol blends on diesel engine performance. Energy Sources, 2002, 24, 431- 440.

[6] Sahin, Z.; Durgun, O. Theoretical investigation of effects of light fuel fumigation on diesel engine performance and emissions. Energy Convers. Manag., 2007, 48, 1952-1964. 